\title{
Dysmotility Symptoms Are Independently Associated With Weight Change: A Population-based Study of Australian Adults
}

\author{
Guy D Eslick, ${ }^{1,2 *}$ Stuart C Howell, ${ }^{1,2}$ and Nicholas J Talley ${ }^{2,3}$ \\ ${ }^{1}$ School of Public Health, The University of Sydney, Sydney, New South Wales, Australia; ${ }^{2}$ Department of Medicine, The University of Sydney, \\ Nepean Hospital, Pentith, New South Wales, Australia; and ${ }^{3}$ Faculty of Health, The University of Newcastle, Callaghan, New South Wales, Australia
}

\begin{abstract}
Background/Aims
Weight loss is a recognized alarm symptom for organic gastrointestinal (GI) disease, yet the association between weight change (loss or gain) and specific Gl symptoms remains poorly described. We assess the associations between Gl symptoms and weight change in a population-based sample of Australian adults.
\end{abstract}

\section{Methods}

The prevalence of $26 \mathrm{Gl}$ symptoms was determined by a postal survey to 5000 residents in western Sydney, Australia (60\% response rate). These were classified a priori into 5 symptom groups-abdominal pain, esophageal symptoms, dysmotility symptoms, diarrhea and constipation. Weight change was measured by two items which assessed weight loss and weight gain. Clinically relevant weight change was defined as a loss or gain of 3 or more kilograms in the past 3 months.

\section{Results}

Prevalence estimates for clinically relevant weight loss and gain in the past 3 months were $10.3 \%$ and $8.1 \%$, respectively. When the 5 symptom groups were evaluated simultaneously, the dysmotility symptoms of fullness after meals emerged as a predictor of both weight loss $(\mathrm{OR}, 1.57 ; 95 \% \mathrm{Cl}, 1.32-1.88 ; P<0.001)$ and weight gain $(\mathrm{OR}, 0.85 ; 95 \% \mathrm{Cl}, 0.72-0.99 ; P=0.040)$, which also included bloating (OR, 1.64; $95 \% \mathrm{Cl} 1.46-1.84 ; P<0.001)$. The associations remained significant following adjustment for socio-economic status, body mass index, and eating behaviors.

\section{Conclusions}

Specific dysmotility symptoms are independently predictive of both weight loss and weight gain. Different pathogenic mechanisms may be involved.

(J Neurogastroenterol Motil 2015;21:603-611)

\section{Key Words}

Body mass index; Gastrointestinal diseases; Prevalence; Weight gain; Weight loss

Received: October 16, 2014 Revised: April 16, 2015 Accepted: July 16, 2015

(c) This is an Open Access article distributed under the terms of the Creative Commons Attribution Non-Commercial License (http://creativecommons. org/licenses/by-nc/4.0) which permits unrestricted non-commercial use, distribution, and reproduction in any medium, provided the original work is properly cited.

*Correspondence: Guy D Eslick, DrPH

Department of Surgery, The Whiteley-Martin Research Center, Nepean Hospital, Clinical Building, Level 3, P.0. Box 63, Penrith, NSW 2751, Australia

Tel: +61-2-47-341-373, Fax: +61-2-47-343-432, E-mail: eslickg@med.usyd.edu.au

Financial support: None.

Conflicts of interest: None.

Author contributions: Guy D Eslick and Nicholas J Talley contributed to the conception and the design of the integrated analysis; Stuart C Howell and Guy D Eslick performed the statistical analyses; and all authors participated in the interpretation of the data and contributed to draft, review and/or revision of the manuscript.

ORCID: Guy D Eslick, http://orcid.org/0000-0002-0098-1705. 


\section{Introduction}

Gastrointestinal (GI) symptoms are common in the community, however, there are few data on the epidemiology and relationship between GI symptoms and obesity. ${ }^{1,2}$ In the United States, the rates of obesity and morbid obesity have increased dramatically over the last 5 decades, with those classified as being overweight remaining fairly stable during this time period. ${ }^{1}$ The financial and functional impact of obesity is enormous. ${ }^{3,4}$ In Australia, there is a similar trend, with the prevalence rates for those being overweight and obese having doubled in the last 20 years. ${ }^{5}$ While the rates of obesity are increasing, our understanding of the biology, genetics, and environmental relationships remains poorly understood. ${ }^{6,7}$ As food intake is potentially related to precipitating either upper or lower GI symptoms, ${ }^{8}$ knowledge of how these symptoms are affected by weight change (weight gain or weight loss) may be important.

Weight loss is a recognized alarm symptom for organic GI disease, ${ }^{9}$ yet the association between weight change (loss or gain) and specific GI symptoms remains poorly described and understood. Gastric disaccommodation has been linked to weight loss in a minority of patients with functional dyspepsia and early satiety, presumably because these patients feel so uncomfortable after eating a small amount. ${ }^{10}$ Many patients with irritable bowel syndrome also have postprandial distress but weight loss is not a recognized characteristic of this syndrome. ${ }^{11}$ On the other hand, increasing body mass index (BMI) has been linked to diarrhea in several populationbased studies, ${ }^{12-16}$ while other studies have not found diarrhea to be significantly related. ${ }^{17-20}$ How upper and lower GI symptoms are affected by weight change (weight gain or weight loss) deserves further exploration. For example, it is unclear if eating behaviors account for any relationship between weight change and gut symptoms.

Therefore, we aimed to determine the prevalence of upper and lower GI symptoms and the relationship with weight change among a community sample of individuals in Australia. We hypothesized that weight gain would be associated with an increased prevalence of diarrhea symptoms, while weight loss would be linked to dysmotility symptoms.

\section{Materials and Methods}

\section{Subjects}

This study was approved by the Sydney West Area Health
Service (SWAHS) Ethics Committee. A total of 5000 adult subjects ( $\geq 18$ years) were randomly selected from the electoral rolls of all local government areas (LGA's) included in the region covered by the Sydney West Area Health Service.

Subjects come from the SWAHS catchment area which consists of a population of 307787 (7.7\% of the Sydney population) and is socio-demographically very similar to the Australian population according to 2006 Census data, except that its inhabitants are slightly younger (32 vs 37 median years) and it has a slightly higher socioeconomic status based on income (\$1285 vs \$1171 median individual income per week), respectively. Ethnic status (those born overseas) was similar (22.2\% vs 20.5\%), with the majority Caucasian based on Australian Bureau of Statistics data (www.abs.gov.au).

\section{Procedures}

A letter was sent to all randomly selected individuals. This letter outlined the study and requested participation. Included with the letter were the Bowel and Stomach Symptoms and Eating Patterns Questionnaire (BSSEPQ), which is made up of other validated instruments. A reminder letter was sent three and six weeks after the initial mail-out. At week 6 this included another questionnaire. The survey was closed at 10 weeks. A prepaid return envelope was included to allow subjects to return the completed questionnaire. Subjects who indicated at any point that they did not wish to participate were not contacted further. A database linking record numbers to identifying information (eg, names and addresses) was stored on an isolated, secured and password protected computer.

Of the 5000 people in the general community to whom we sent the questionnaire, a total of 2935 questionnaires were returned (complete and incomplete). There were 142 questionnaires sent back for various reasons (eg, death, gone overseas, did not want to participate, wrong address, mentally ill, too sick to participate, and in jail). The response rate was $60 \%$, with $54 \%$ being female.

\section{Definitions}

\section{Weight change}

Weight change was evaluated by 3 items which sought information about unintentional weight gain (1 item) and weight loss (2 items) over a 3-month pre-survey period. These were treated as separate outcome measures and defined as follows:

(1) Weight gain: a gain of 3 or more kilograms over the preceding 3 months in the absence of a deliberate attempt to 
gain weight.

(2) Weight loss: a loss of 3 or more kilograms over the preceding 3 months in the absence of deliberate dieting.

The clinically relevant change in weight of 3 kilograms was equivalent to $5 \%$ of the mean body weight of the participants in the study.

\section{Gastrointestinal symptoms}

The survey instrument included 26 items, which evaluated common symptoms emanating from the upper and lower GI tract. These assessed frequency over a 3 month pre-survey period according to a 5 point graded scale. The following response options were available: not at all, sometimes, often, very often, and almost always. The symptom items were dichotomized to reflect symptom absent (not at all and sometimes) vs symptom present (often or more frequently) and classified broadly based on Rome II criteria although specific criteria were not applied. ${ }^{21}$ The following groups were defined a priori:

(1) Abdominal pain: pain or discomfort in abdomen

(2) Esophageal symptoms: one or more of heartburn, acid regurgitation, and dysphagia

(3) Dysmotility symptoms: one or more of early satiety, postprandial fullness, sensation of abdominal bloating, and visible abdominal distension

(4) Nausea and/or vomiting: one or more of nausea, vomiting, and retching

(5) Diarrhea: one or more of three or more bowel movements daily, loose or watery stools, urgency, and leakage of bowel movements

(6) Constipation: one or more of less than three bowel movements weekly, hard or lumpy stools, straining on defecation, and incomplete evacuation

\section{Socioeconomic status and health risk status}

Responder age and gender were evaluated along with marital status (married vs unmarried), country of birth (Australian- vs overseas-born) and highest level of completed (secondary and tertiary) education. The latter was classified as High (University qualifications) vs Medium (minimum of Year 12 or Year 10 plus a tertiary [but non-university] qualification) vs Low (Year 10 or less). Common health-risk behaviors were also assessed including smoking status (current smoker vs non-smoker), alcohol consumption (number of standard drinks usually consumed on any drinking occasion) and daily intake of caffeinated, sweetened, and diet beverages. Responders were asked to report any diag- nosis of diabetes mellitus. BMI was calculated from self reported height and weight using the formula: BMI $=$ [weight $(\mathrm{kg})] /[\text { height }(\mathrm{m})]^{2}$.

\section{Eating behaviors}

The questionnaire included items drawn from the Family Eating and Activity Habits Questionnaire (FEAHQ) ${ }^{22}$ and the Questionnaire on Eating and Weight Patterns (QEWP). ${ }^{23}$ These are validated instruments which evaluate habits and perceptions in relation to normal eating behavior. The following measures were applied in this study: self-perceived eating pace (fast vs average or slow), eating when bored or angry (frequently or always), late night snacking (weekly or more often), self-reported overeating, preoccupation with weight (weighs weekly or more often) and concern with overeating and with control over eating behavior (greatly or extremely concerned). Consumption of fried foods and red meat were also assessed (weekly or more often).

\section{Quality of life}

Quality of life (QOL) as evaluated using the short form of the Nepean Dyspepsia Index (NDI). ${ }^{24}$ This is a 10 -item scale which evaluates disease-specific QOL across 5 domains - tension, interference with daily activities, eating/drinking, disease-specific knowledge and control, and work or study. Each domain is assessed by 2 items which are scored according to a 5 point scale. The item responses are summed to provide a domain subscale score ranging from 2 (no impairment to QOL) to 10 (extreme impairment). The NDI short form is a responsive disease-specific instrument with established psychometric properties.

Preliminary analysis showed that scores on the 5 QOL domains were heavily skewed with the majority of responders indicating no or little impairment to QOL. Thus, for the purposes of analysis, the subscale scores were dichotomized by applying a cutoff of 10 points. $^{25}$ This cutoff indicates moderate or greater impairment to QOL on at least one of the items used to evaluate the QOL domain.

\section{Statistical Methods}

Weight gain and weight loss were evaluated separately as outcomes and the data is summarized as prevalence estimates. These are also stratified by key predictor measures including socioeconomic status, health and eating behaviors, and NDI QOL. Univariate associations are evaluated using Pearson's Chi-squared statistics. Logistic regression was applied to identify significant 
and independent predictors of weight gain and weight loss. The most parsimonious model was sought in both cases, and backward, stepwise eliminated was applied for model reduction. Hypothesis tests were two-tailed in all analyses, and an alpha-level of 0.05 was applied.

\section{Results}

\section{Weight Gain}

Clinically relevant weight gain ( 3 or more kilograms) was reported by 213 responders, yielding a prevalence estimate of $8.1 \%$ (95\% CI, 7.0-9.1\%). This was significantly higher among females compared to males $(9.8 \%$ vs $6.1 \%, P<0.001)$ and was associated with a younger responder age (mean age: gain vs no gain [41.9 vs 45.9] years, $P<0.001)$.

The prevalence of weight gain was significantly higher

Table 1. Prevalence of Weight Loss and Weight Gain Stratified by Symptom Group

\begin{tabular}{|c|c|c|}
\hline & $\begin{array}{c}\text { Weight gain } \\
\text { (2636) }\end{array}$ & $\begin{array}{c}\text { Weight Loss } \\
\quad(2632)\end{array}$ \\
\hline Prevalence (\%) & 8.1 & 10.3 \\
\hline \multicolumn{3}{|l|}{ Symptoms (\%) } \\
\hline \multicolumn{3}{|l|}{ Pain } \\
\hline No & 7.2 & 9.4 \\
\hline Yes & 12.1 & 15.4 \\
\hline$P$-value & 0.001 & $<0.001$ \\
\hline \multicolumn{3}{|l|}{ Esophageal } \\
\hline No & 7.1 & 9.8 \\
\hline Yes & 13.7 & 13.5 \\
\hline$P$-value & $<0.001$ & 0.040 \\
\hline \multicolumn{3}{|l|}{ Dysmotility } \\
\hline No & 5.8 & 8.8 \\
\hline Yes & 16.0 & 16.4 \\
\hline$P$-value & $<0.001$ & $<0.001$ \\
\hline \multicolumn{3}{|l|}{ Vomiting } \\
\hline No & 7.4 & 10.0 \\
\hline Yes & 20.4 & 15.8 \\
\hline$P$-value & $<0.001$ & 0.030 \\
\hline \multicolumn{3}{|l|}{ Diarrhea } \\
\hline No & 6.8 & 9.3 \\
\hline Yes & 11.8 & 13.5 \\
\hline$P$-value & $<0.001$ & 0.002 \\
\hline \multicolumn{3}{|l|}{ Constipation } \\
\hline No & 6.7 & 9.6 \\
\hline Yes & 13.8 & 13.2 \\
\hline$P$-value & $<0.001$ & 0.020 \\
\hline
\end{tabular}

among responders who reported GI complaints (Table 1). This held for all symptom categories evaluated (Table 1), although the differences were particularly pronounced in relation to dysmotility symptoms $(16.0 \%$ vs $5.8 \%, P<0.001)$ and nausea/vomiting $(20.4 \%$ vs $7.4 \%, P<0.001)$. Weight gain was also associated with a higher consumption of sweetened and diet beverages $(P=0.002$ and $P<0.001$, respectively; Table 2$)$, obesity $(P<0.001$; Table 2$)$, and various eating behaviors (Table 3$)$, including a faster eating pace $(P=0.002)$, eating when bored $(P$ $<0.001)$ or angry $(P<0.001)$, and frequently eating late at night $(P=0.010)$. It was also associated with greater concerns in relation to overeating $(P<0.001$; Table 3$)$ and control over eating behavior $(P<0.001$; Table 3$)$. Finally, weight gain was typically more common among individuals who reported at least moderate impairment to QOL as established by the 5 subscales of the NDI (Table 3).

Table 2. Prevalence of Weight Loss and Gain Stratified by Socioeconomic Measures and Key Health Risk Factors

\begin{tabular}{|c|c|c|}
\hline & $\begin{array}{c}\text { Weight gain } \\
\quad(2636)\end{array}$ & $\begin{array}{c}\text { Weight Loss } \\
\quad(2632)\end{array}$ \\
\hline Prevalence (\%) & 8.1 & 10.3 \\
\hline \multicolumn{3}{|c|}{ Marital status (\%) } \\
\hline Married & 7.8 & 9.4 \\
\hline Single & 9.1 & 13.5 \\
\hline$P$-value & 0.300 & 0.005 \\
\hline \multicolumn{3}{|c|}{ Country of birth (\%) } \\
\hline Australia & 8.2 & 10.3 \\
\hline Overseas & 7.8 & 10.0 \\
\hline$P$-value & 0.770 & 0.870 \\
\hline \multicolumn{3}{|l|}{ Education (\%) } \\
\hline High & 7.1 & 9.6 \\
\hline Medium & 8.0 & 10.9 \\
\hline Low & 8.9 & 9.9 \\
\hline$P$-value & 0.480 & 0.640 \\
\hline \multicolumn{3}{|c|}{ Diabetes mellitus (\%) } \\
\hline No & 8.0 & 9.9 \\
\hline Yes & 8.3 & 15.9 \\
\hline$P$-value & 0.900 & 0.020 \\
\hline \multicolumn{3}{|c|}{ Current smoker (\%) } \\
\hline No & 8.0 & 9.2 \\
\hline Yes & 7.9 & 15.1 \\
\hline$P$-value & 0.940 & $<0.001$ \\
\hline \multicolumn{3}{|l|}{ Alcohol (\%) } \\
\hline None & 7.7 & 9.1 \\
\hline 1-2 drinks & 7.2 & 10.3 \\
\hline 3-4 drinks & 8.9 & 10.1 \\
\hline $5+$ drinks & 10.3 & 12.9 \\
\hline$P$-value & 0.280 & 0.390 \\
\hline
\end{tabular}


Table 3. Prevalence of Weight Loss and Gain Stratified by Measures of Eating Behavior and Scores on the Nepean Dyspepsia Index Quality of Life Scales

\begin{tabular}{|c|c|c|}
\hline & $\begin{array}{c}\text { Weight gain } \\
\quad(2636)\end{array}$ & $\begin{array}{c}\text { Weight loss } \\
\quad(2632)\end{array}$ \\
\hline Prevalence $(\%)$ & 8.1 & 10.3 \\
\hline \multicolumn{3}{|l|}{ Eating pace (\%) } \\
\hline Slow/average & 7.1 & 11.2 \\
\hline Fast & 11.0 & 7.5 \\
\hline$P$-value & 0.002 & 0.007 \\
\hline \multicolumn{3}{|l|}{ Eating when bored (\%) } \\
\hline Never/infrequently & 6.2 & 10.6 \\
\hline Frequently/always & 17.5 & 8.5 \\
\hline$P$-value & $<0.001$ & 0.180 \\
\hline \multicolumn{3}{|l|}{ Eating when angry $(\%)$} \\
\hline Never/infrequently & 6.7 & 10.5 \\
\hline Frequently/always & 21.3 & 8.7 \\
\hline$P$-value & $<0.001$ & 0.390 \\
\hline \multicolumn{3}{|l|}{ Frequency of weighing (\%) } \\
\hline Monthly or less & 7.4 & 10.4 \\
\hline Weekly or more often & 9.6 & 10.2 \\
\hline$P$-value & 0.060 & 0.930 \\
\hline \multicolumn{3}{|l|}{ Consumption of fried food (\%) } \\
\hline Less than once per week & 7.5 & 10.2 \\
\hline More than once per week & 9.6 & 10.7 \\
\hline$P$-value & 0.070 & 0.690 \\
\hline \multicolumn{3}{|l|}{ Consumption of red meat (\%) } \\
\hline Less than once per week & 9.3 & 9.8 \\
\hline More than once per week & 7.6 & 10.5 \\
\hline$P$-value & 0.190 & 0.590 \\
\hline \multicolumn{3}{|c|}{ Frequency of late night eating (\%) } \\
\hline Less than once per week & 7.1 & 8.9 \\
\hline More than once per week & 9.9 & 12.8 \\
\hline$P$-value & 0.010 & 0.002 \\
\hline
\end{tabular}

Table 4 shows the independent predictors of weight gain as identified by logistic regression. The odds of weight gain were significantly higher amongst individuals who reported bloating (OR, 1.64; 95\% CI, 1.46-1.84; $P<0.001$ ) but lower among individuals who reported fullness after meals (OR, $0.85 ; 95 \% \mathrm{CI}$, $0.73-0.99 ; P=0.040)$. There were graded associations which indicated that the odds of weight gain increased in conjunction with both increasing BMI (trend: $P<0.001$ ) and a higher consumption of diet beverages (trend: $P=0.020$ ), but decreased with increasing age (OR, 0.86; 95\% CI, 0.80-0.93; $P<0.001)$. Weight gain was independently related to eating when bored (OR, 1.79; 95\% CI, 1.25-2.57; $P=0.001)$ and with greater concerns over eating behavioral control (OR, 2.64; 95\% CI, 1.63-4.29; $P<0.001)$.

\begin{tabular}{|c|c|c|}
\hline & $\begin{array}{c}\text { Weight gain } \\
\quad(2636)\end{array}$ & $\begin{array}{c}\text { Weight loss } \\
\text { (2632) }\end{array}$ \\
\hline Prevalence (\%) & 8.1 & 10.3 \\
\hline \multicolumn{3}{|l|}{ Upset by overeating (\%) } \\
\hline Not greatly & 6.8 & 10.2 \\
\hline Greatly or extremely & 27.4 & 10.9 \\
\hline$P$-value & $<0.001$ & 0.790 \\
\hline \multicolumn{3}{|c|}{ Lack control over eating $(\%)$} \\
\hline Not greatly & 6.8 & 10.2 \\
\hline Greatly or extremely & 33.1 & 10.0 \\
\hline$P$-value & $<0.001$ & 0.950 \\
\hline \multicolumn{3}{|l|}{ NDI: Tension (\%) } \\
\hline Little impairment & 7.3 & 9.8 \\
\hline At least moderate & 16.8 & 16.8 \\
\hline$P$-value & $<0.001$ & 0.001 \\
\hline \multicolumn{3}{|l|}{ NDI: Activity (\%) } \\
\hline Little impairment & 7.4 & 10.2 \\
\hline At least moderate & 22.4 & 13.2 \\
\hline$P$-value & $<0.001$ & 0.310 \\
\hline \multicolumn{3}{|l|}{ NDI: Appetite (\%) } \\
\hline Little impairment & 7.3 & 9.5 \\
\hline At least moderate & 15.6 & 18.6 \\
\hline$P$-value & $<0.001$ & $<0.001$ \\
\hline \multicolumn{3}{|l|}{ NDI: Control (\%) } \\
\hline Little impairment & 7.4 & 9.7 \\
\hline At least moderate & 13.9 & 16.4 \\
\hline$P$-value & $<0.001$ & 0.001 \\
\hline \multicolumn{3}{|c|}{ NDI: Work and study (\%) } \\
\hline Little impairment & 7.7 & 9.9 \\
\hline At least moderate & 16.3 & 19.4 \\
\hline$P$-value & 0.001 & 0.001 \\
\hline
\end{tabular}

\section{Weight Loss}

Clinically relevant weight loss (3 or more kilograms) was reported by 271 responders, yielding a prevalence estimate of $10.3 \%$ (95\% CI, 9.1-11.5). This did not vary according to responder gender (females vs males [10.0\% vs $10.5 \%$ ], $P=0.690$ ), but was significantly associated with lower responder age (mean age: loss vs no loss [42.3 vs 45.9] years), $P<0.001$ ).

Weight loss was typically more common among responders who reported GI complaints (Table 1); significant differences were observed on all symptom groups evaluated, although the effects were not as pronounced as they were in relation to weight gain. The prevalence of weight loss was significantly associated with marital status $(P=0.005$; Table 2$)$, a history of diabetes mellitus $(P=0.020$; Table 2$)$, and current smoking status $(P<$ 0.001 ; Table 2$)$. However, it was generally independent of other 
Table 4. Independent Predictors of Weight Gain

\begin{tabular}{|c|c|c|c|}
\hline & Odds ratio & $95 \% \mathrm{CI}$ & $P$-value \\
\hline \multicolumn{4}{|l|}{ Dysmotility Symptoms } \\
\hline Fullness after meals & 0.85 & $0.72-0.99$ & 0.040 \\
\hline Bloating & 1.64 & $1.46-1.84$ & $<0.001$ \\
\hline \multicolumn{4}{|l|}{ SES/lifestyle factors } \\
\hline Age & 0.86 & $0.80-0.93$ & $<0.001$ \\
\hline \multicolumn{4}{|l|}{ Diet drinks } \\
\hline None & 1.00 & - & \\
\hline $1-2$ & 1.68 & $1.15-2.45$ & 0.010 \\
\hline 3 or more & 1.54 & $0.93-2.55$ & 0.090 \\
\hline$P$-value for trend & 0.02 & & \\
\hline \multicolumn{4}{|l|}{ BMI } \\
\hline Underweight/normal & 1.00 & - & - \\
\hline Overweight & 1.87 & $1.23-2.84$ & 0.004 \\
\hline Obese & 2.96 & $1.94-4.52$ & $<0.001$ \\
\hline$P$-value for trend & $<0.001$ & & \\
\hline \multicolumn{4}{|l|}{ Eating behavior } \\
\hline Eating when bored & 1.79 & $1.25-2.57$ & 0.001 \\
\hline No control & 2.64 & $1.63-4.29$ & $<0.001$ \\
\hline
\end{tabular}

SES, socio-economic status; BMI, body mass index.

socio-economic status measures and health risk factors. Weight loss was typically associated with a slower eating pace $(P=$ 0.007; Table 3$)$ and with frequently eating late at night $(P=$ 0.002; Table 3). It was also associated with moderate impairment to QOL on 4 of the $5 \mathrm{NDI}$ subscales (tension: $P=0.001$; appetite: $P<0.001$; control: $P=0.001$; Work and study: $P=0.001$ ) (Table 3).

The independent predictors of weight loss are shown in the Table 5. The odds of weight loss were significantly elevated among individuals who reported fullness after meals (OR, 1.57; 95\% CI, 1.32-1.88; $P<0.001)$. Weight loss was also associated with a history of diabetes (OR, 2.25; 95\% CI, 1.41-3.60; $P=$ $0.001)$, those who were current smokers (OR, 1.52; 95\% CI, 1.13-2.05; $P=0.006$ ), and/or reported impaired QOL of the NDI Appetite scale, but were lower amongst those reporting a fast eating pace (OR, 0.58; 95\% CI, 0.42-0.81; $P=0.002)$. Increasing age was associated with a reduction in the odds of weight loss.

\section{Discussion}

In this population-based study we found that there were specific dysmotility symptoms (postprandial fullness and abdominal bloating, or visible abdominal distension) which were independently predictive of both weight loss and weight gain. The associ-
Table 5. Independent Predictors of Weight Loss

\begin{tabular}{lccc}
\hline & Odds ratio & $95 \% \mathrm{CI}$ & $P$-value \\
\hline $\begin{array}{l}\text { Dysmotility Symptoms } \\
\quad \text { Fullness after meals }\end{array}$ & 1.57 & $1.32-1.88$ & $<0.001$ \\
SES/lifestyle factors & & & \\
$\quad$ Age & 0.86 & $0.86-0.91$ & $<0.001$ \\
$\quad$ Diabetes & 2.25 & $1.41-3.60$ & 0.001 \\
$\quad$ Current smoker & 1.52 & $1.13-2.05$ & 0.006 \\
Eating behavior & & & \\
$\quad$ Fast eating pace & 0.58 & $0.42-0.81$ & 0.002 \\
$\quad$ Late night eating & 1.30 & $1.00-1.70$ & 0.050 \\
Quality of life & & & \\
$\quad$ Appetite & 1.57 & $1.06-2.32$ & 0.020 \\
\hline SES, & & &
\end{tabular}

SES, socio-economic status.

ation was stronger for weight loss compared to weight gain for postprandial fullness and only bloating was associated with weight gain. Consumption of diet soft drinks, eating when bored and no control over eating behaviors were all independent predictors of weight gain among this community sample. However, diabetes mellitus, current smoking, late night eating, and appetite were all independent predictors of weight loss. Moreover, increasing age was independently associated with a reduction in the odds of weight loss.

All of the GI symptom groups were associated with weight change (Table 1), but this was not the picture when confounding was considered in the analyses. We could not confirm diarrhea was independently linked to weight gain although we have shown a link to obesity in previous population-based studies. ${ }^{14,15}$ The present study is the first to assess lower GI symptoms and weight change, previous studies have only assessed upper GI symptoms and weight change ${ }^{19}$ or BMI and GI symptoms. ${ }^{12-16}$

No previous studies have reported dysmotility symptoms as independent predictors of both weight gain and weight loss. However, a prospective study $(n=637)$ from the United States did find that an increase in body weight of $4.5 \mathrm{~kg}$ was strongly linked to patients with dyspepsia and dysmotility, which was defined as subjects reporting nausea, vomiting, upper abdominal bloating, or early satiety (OR, 5.57; 95\% CI: 1.91-16.2). ${ }^{19}$ Weight loss has been linked to fundic disaccommodation and early satiety. ${ }^{26}$ Gastroparesis can lead to weight loss. ${ }^{27,28}$ There are also rare conditions such as mitochondrial neurogastrointestinal encephalomyopathy (MNGIE) associated with weight loss and dysmotility symptoms. ${ }^{29}$ This is why we hypothesized weight loss would be found in association with dysmotility symptoms. Univariately, both weight gain and weight loss were linked to 
symptoms of nausea and/or vomiting, but after adjusting for confounders this was not statistically significant. However, previous research has reported that early satiety and nausea/vomiting are strongly associated with weight loss in dyspeptic patients. ${ }^{9} \mathrm{We}$ adjusted for eating behaviors and other possible confounders, and conclude the associations observed may be of causal importance.

Abnormal eating behaviors were independent predictors of weight change in this study. For those experiencing weight gain, eating when bored and no control were significantly associated and among those experiencing weight loss, a fast eating pace and late night eating were also significant. In a recent study by Cremonini and colleagues ${ }^{30}$ assessed GI symptoms and the relationship with binge eating among a large community sample (n $=4096$ ) in the United States; they found that binge eaters were more likely to be obese and experience statistically significant GI symptoms compared to "over-eaters." These data correlate with our data suggesting that those who gain weight are more likely to be binge eaters and more likely to have GI symptoms. Conversely, those who lost weight where more likely to have different eating behaviors, which include fast eating pace and late night eating. The pathogenic mechanisms associated with the dysmotility symptoms among those experiencing weight gain or loss could be different, but both may relate to the different eating behaviors exhibited by each group. For those individuals experiencing weight loss, slow pace eating and late night eating may be linked to early satiety. Previous data suggests that individuals who eat slowly have significant decreases in energy intake compared with quick eaters (579.0 vs $645.7 \mathrm{kcal}, P<0.05)$, and that they are more likely to experience greater satiety. ${ }^{31}$ Bloating was the most significant dysmotility symptom among those experiencing weight gain. Previous studies have reported that those experiencing bloating are more likely to have recently gained weight ${ }^{32}$ while others have found that obese individuals are more likely to report bloating than non-obese individuals. ${ }^{13,20}$ In another study, morbidly obese individuals undergoing gastric bypass surgery reported higher rates of bloating compared to non-obese controls (26.7\% vs $16.8 \%, P=0.080$ ), but it was not statistically significant. ${ }^{33}$ The mechanism of bloating in those gaining weight or obese could be due to the production of intestinal gas related to changes in microbiological flora in their intestinal tract (eg, bacterial overgrowth), but several pathophysiological mechanisms may be responsible and remain unknown.

We did not measure gastric function in this community sample, but other data suggest abnormalities of gastric emptying are common in those with upper GI symptoms although a link to specific symptoms has been hard to establish. ${ }^{34,35}$ Several studies have assessed gastric emptying using scintigraphy in obese subjects and found that emptying of liquids is similar to healthy controls, ${ }^{36}$ however, emptying of solids paradoxically appears to be accelerated among obese subjects. ${ }^{37-39}$

In this cohort there was no link between weight gain and weight loss with nausea and vomiting, highlighting that these symptoms would have had no effect on necessarily diminishing food intake or that food may be eaten to try and relieve symptoms. Recently, the Gastroparesis Clinical Research Consortium in the United States identified a group of 106 patients with normal gastric emptying and unexplained nausea and vomiting ${ }^{40}$; about half did not fulfill Rome III criteria for a functional GI disorder, but overall this group was indistinguishable symptomatically from patients with documented slow gastric emptying. This sub-group of patients with nausea and vomiting and normal gastric emptying may represent a distinct diagnostic entity, with symptoms persisting for at least 12 months. In our study, it is possible that among those individuals who gained weight and experienced more frequent episodes of vomiting and nausea, there may be a group who deliberately purge (induce vomiting) themselves in order to consume more food (a variant of bulimia nervosa). In fact, a post-hoc analysis revealed that those who gained weight were three times more likely to deliberately induce vomiting after binge eating (OR, 3.17; 95\% CI, 1.51-6.68).

The current study had a number of strengths including the use of a validated questionnaire, a randomly selected and representative population sample, good response rate and almost equal gender groups included. We also attempted to assess other diseases that might be linked with obesity and GI symptoms including diabetes mellitus, which was an independent risk factor for weight loss (although we did not obtain data on how many of these were type I vs type II diabetes). Limitations of this study may also include the self-reported information collected on subject height and weight which may introduce some measurement bias in determining the BMI although validation data suggest this is not a major issue. ${ }^{41}$ Also, the self-reported abdominal circumference which may have been perceived as bloating could also be a potential source of bias in this study.

In conclusion, our study suggests that specific dysmotility symptoms are independent predictors of both weight loss and weight gain. Different pathogenic mechanisms may be involved and these require further investigation. 


\section{References}

1. Eslick GD. Prevalence and epidemiology of gastrointestinal symptoms among normal weight, overweight, obese and extremely obese individuals. Gastroenterol Clin North Am 2010;39:9-22.

2. Foxx-Orenstein AE. Gastrointestinal symptoms and diseases related to obesity: an overview. Gastroenterol Clin North Am 2010;39:23-37.

3. Russell GV, Pierce CW, Nunly L. Financial implications of obesity. Orthop Clin North Am 2011;42:123-127.

4. Li Z, Bowerman S, Heber D. Health ramifications of the obesity epidemic. Surg Clin North Am 2005;85:681-701.

5. Cameron AJ, Welborn TA, Zimmet PZ, et al. Overweight and obesity in Australia: the 1999-2000 Australian Diabetes, Obesity and Lifestyle Study (AusDiab). Med J Aust 2003;178:427-432.

6. Chung WK, Leibel RL. Considerations regarding the genetics of obesity. Obesity 2008;16(suppl 3):S33-S39.

7. Trayhurn P. The biology of obesity. Proc Nutr Soc 2005;64:31-38.

8. Simrén M, Månsson A, Langkilde AM, et al. Food-related gastrointestinal symptoms in the irritable bowel syndrome. Digestion 2001; 63:108-115.

9. Tack J, Jones MP, Karamanolis G, Coulie B, Dubois D. Symptom pattern and pathophysiological correlates of weight loss in tertiary-referred functional dyspepsia. Neurogastroenterol Motil 2010;22: 29-35, e4-e5.

10. Tack J, Caenepeel P, Fischler B, Piessevaux H, Janssens J. Symptoms associated with hypersensitivity to gastric distention in functional dyspepsia. Gastroenterology 2001;121:526-535.

11. Tack J, Talley NJ, Camilleri M, et al. Functional gastroduodenal disorders. Gastroenterology 2006;130:1466-1479.

12. Crowell MD, Cheskin LJ, Musial F. Prevalence of gastrointestinal symptoms in obese and normal weight binge eaters. Am J Gastroenterol 1994;89:387-391.

13. Delgado-Aros S, Locke III GR 3rd, Camilleri M, et al. Obesity is associated with increased risk of gastrointestinal symptoms: a population-based study. Am J Gastroenterol 2004;99:1801-1806.

14. Talley NJ, Howell S, Poulton R. Obesity and chronic gastrointestinal tract symptoms in young adults: a birth cohort study. Am J Gastroenterol 2004;99:1807-1814.

15. Talley NJ, Quan C, Jones MP, Horowitz M. Association of upper and lower gastrointestinal tract symptoms with body mass index in an Australian cohort. Neurogastroenterol Motil 2004;16:413-419.

16. Aro P, Ronkainen J, Talley NJ, Storskrubb T, Bolling-Sternevald E, Agréus L. Body mass index and chronic unexplained gastrointestinal symptoms: an adult endoscopic population based study. Gut 2005; 54:1377-1383.

17. Foster A, Richards WO, McDowell J, Laws HL, Clements RH. Gastrointestinal symptoms are more intense in morbidly obese patients. Surg Endosc 2003;17:1766-1768.

18. van Oijen MG, Josemanders DF, Laheij RJ, van Rossum LG, Tan AC, Jansen JB. Gastrointestinal disorders and symptoms: does body mass index matter? Neth J Med 2006;64:45-49.

19. Cremonini F, Locke GR 3rd, Schleck CD, Zinsmeister AR, Talley NJ. Relationship between upper gastrointestinal symptoms and changes in body weight in a population-based cohort. Neurogastro- enterol Motil 2006;18:987-994

20. Pourhoseingholi MA, Kaboli SA, Pourhoseingholi A, et al. Obesity and functional constipation: a community-based study in Iran. J Gastrointestin Liver Dis 2009;18:151-155.

21. Drossman DA. The functional gastrointestinal disorders and the Rome II process. Gut 1999;45(suppl 2):II1-II5.

22. Golan M, Weizman A. Reliability and validity of the family eating and activity habits questionnaire. Eur J Clin Nutr 1998;52:771-777.

23. Nangle DW, Johnson, WG, Carr-Nangle RE, Engler LB. Binge eating disorder and the proposed DSM-IV criteria: psychometric analysis of the questionnaire of eating and weight patterns. Int J Eat Disord 1994;16:147-157.

24. Talley NJ, Haque M, Wyeth JW, et al. Development of a new dyspepsia impact scale: the Nepean Dyspepsia Index. Aliment Pharmacol Ther 1999;13:225-235.

25. Jones M, Talley NJ. Minimum clinically important difference for the Nepean Dyspepsia Index, a validated quality of life scale for functional dyspepsia. Am J Gastroenterol 2009;104:1483-1488.

26. Tack J, Piessevaux H, Coulie B, Caenpeel P, Janssens J. Role of impaired gastric accommodation to a meal in functional dyspepsia. Gastroenterology 1998;115:1346-1352.

27. Bouras EP, Lange SM, Scolapio JS. Rational approach to patients with unintentional weight loss. Mayo Clin Proc 2001;76:923-929.

28. Karamanolis G, Caenepeel P, Arts J, Tack J. Determinants of symptom pattern in idiopathic severely delayed gastric emptying: gastric emptying rate or proximal stomach dysfunction? Gut 2007;56:29-36.

29. Parry-Jones A, Paine P, Ramdass R, et al. Unexplained gastrointestinal dysmotility: the clue may lie in the brain. Gut 2011;60:758.

30. Cremonini F, Camilleri M, Clark MM, et al. Associations among binge eating behavior patterns and gastrointestinal symptoms: a population-based study. Int J Obes 2009;33:342-353.

31. Andrade AM, Greene GW, Melanson KJ. Eating slowly led to decreases in energy intake within meals in healthy women. J Am Diet Assoc 2008;108:1186-1191.

32. Sullivan SN. A prospective study of unexplained visible abdominal bloating. N Z Med J 1994;107:428-430.

33. Dutta SK, Arora M, Kireet A, Bashandy H, Gandsas A. Upper gastrointestinal symptoms and associated disorders in morbidly obese patients: a prospective study. Dig Dis Sci 2009;54:1243-1246.

34. Haag S, Talley NJ, Holtmann G. Symptom patterns in functional dyspepsia and irritable bowel syndrome: relationship to disturbances in gastric emptying and response to a nutrient challenge in consulters and non-consulters. Gut 2004;53:1445-1451.

35. Talley NJ, Locke GR 3rd, Tack J. Does delayed gastric emptying really cause symptoms in functional dyspepsia? We still doubt it! Gut 2006;55:1674.

36. Horowitz M, Collins PJ, Shearman DJ. Effect of increasing the caloric/osmotic content of the liquid component of a mixed solid and liquid meal on gastric emptying in obese subjects. Hum Nutr Clin Nutr 1986;40:51-56.

37. Tosetti C, Corinaldesi R, Stanghellini V, et al. Gastric emptying of solids in morbid obesity. Int J Obes Relat Metab Disord 1996;20: 200-205.

38. Wright RA, Krinsky S, Fleeman C, Trujillo J, Teague E. Gastric emptying and obesity. Gastroenterology 1983;84:747-751.

39. Xing J, Chen JD. Alterations of gastrointestinal motility in obesity. 
Obes Res 2004;12:1723-1732.

40. Pasricha PJ, Colvin R, Yates K, et al. Characteristics of patients with chronic unexplained nausea and vomiting and normal gastric emptying. Clin Gastroenterol Hepatol 2011;9:567-576, e1-e4.
41. Dekkers JC, van Wier MF, Hendriksen IJM, Twisk JW, van Mechelen W. Accuracy of self-reported body weight, height and waist circumference in a Dutch overweight working population. BMC Med Res Methodol 2008;8:69. 